\title{
Uma Proposta de uso do Winplot no Ensino de Funções Quadráticas nas Turmas do PROEJA
}

\author{
A Proposal for the use of Winplot in the Teaching of Quadratic Functions in \\ Classes of PROEJA
}

\author{
Rodrigo Carvalho Dias ${ }^{1}$, Edson Luiz Kraemer² e César de Oliveira Zica ${ }^{3}$ \\ 1,2,3Professores, Instituto Federal de Educação, Ciência e Tecnologia do Tocantins - Campus Palmas, Brasil \\ carvalhodias@ifto.edu.br; edson@ifto.edu.br; cesarzica@gmail.com
}

\begin{abstract}
Resumo
Diante das dificuldades relacionadas à compreensão dos conteúdos de matemática por grande parte dos estudantes que ingressam no Ensino Médio, propõem-se neste trabalho algumas atividades voltadas para o ensino de funções quadráticas com o auxílio do software winplot. A princípio essas atividades foram elaboradas para as turmas do primeiro semestre dos cursos do PROEJA (são cursos do Programa Nacional de Integração da Educação Profissional com a Educação Básica na Modalidade de Jovens e Adultos) do Instituto Federal do Tocantins, entretanto este trabalho pode ser útil a qualquer aluno que esteja estudando função quadrática. As atividades propostas não têm a finalidade de substituir o tratamento algébrico e formal do ensino de funções, mas oferecer ao professor e ao aluno uma opção interessante para construção de gráficos de forma mais ágil e interativa. Por meio do recurso de animações de gráficos, pretende-se conjecturar algumas relações entre os parâmetros e o comportamento do gráfico, apresentando sempre ao final das atividades uma justificativa matemática para as relações obtidas.
\end{abstract}

Palavras-chave: Função Quadrática, Software Winplot, Parêmetros.

\begin{abstract}
In the light of the difficulties most first-year students at high school face regarding the learning of mathematics contents, this study proposes some activities aiming at teaching square function using the win-plot software as a tool. At the beginning these activities were designed to be applied in the first year of the PROEJA course (a high school course integrated to a technical one for adult learners) at Instituto Federal do Tocantins, however it can be useful for any student who is learning square function. The activities proposed do not intend to replace the formal and algebraic teaching of the subject, yet they aim to offer teachers and students an interesting option to build graphs in an interactive and agile way. Through graph animation tools, we intend to make some relations between the parameters and the behavior of the graph, always presenting the mathematics explanation of the relation observed at the end of the activity.
\end{abstract}

Keywords: quadratic function, winplot software, parameters. 


\section{Introdução}

Em uma entrevista realizada para a TV Educativa do Rio de Janeiro e concedida no capítulo 1 do livro Matemática e Ensino, o professor Elon Lages Lima destaca que o conhecimento matemático é, por natureza, encadeado e cumulativo. Diz ainda que "esse aspecto de dependência acumulativa dos assuntos matemáticos leva a uma sequência necessária, que torna difícil pegar o bonde andando e muitas vezes provoca uma síndrome conhecida como ansiedade matemática"1. Dessa forma, os primeiros anos do Ensino Fundamental podem ser decisivos na formação da opinião dos estudantes em relação à matemática.

A transição do estudante do Ensino Fundamental para o Ensino Médio pode evidenciar ainda mais as distorções do conhecimento matemático acumulado ao longo de todo Ensino Fundamental. Esse fato pode se agravar em alguns casos, principalmente quando houver uma lacuna entre o término do Ensino Fundamental e o início do Ensino Médio.

Em geral, uma criança ingresssa no Ensino Fundamental aos sete anos de idade e conclui aos 14 ou 15 anos. Em alguns programas nacionais, como o PROEJA, os estudantes podem ingressar no Ensino Médio aos 18 anos de idade. Porém, segundo informações repassadas informalmente pela secretaria escolar do Campus Palmas, em julho de 2013, o cenário é ainda mais preocupante. Verificou-se que, nas turmas do primeiro ano do PROEJA no IFTO - Campus Palmas, os estudantes têm em média 28 anos de idade. Esse intervalo de 13 a 14 anos, compreendido entre o término do Ensino Fundamental e o início do Ensino Médio, acrescido do fato desse programa reduzir a dois anos a conclusão do Ensino Médio, pode tornar ainda mais evidente os problemas com a aprendizagem dos conteúdos de matemática.

Nesse sentido, pretende-se com este trabalho apresentar ao professor uma proposta diferenciada para o ensino de função quadrática nas turmas do $1^{\circ}$ ano do PROEJA com o objetivo de contribuir na redução das distorções do conhecimento matemático relativo a esse conteúdo.

O Programa Nacional de Intergração da Educação Profissional com a Educação Básica na Modalidade de Jovens e Adultos (PROEJA) é oferecido para estudantes com mais de 17 anos que tenham concluído o Ensino Fundamental. O Documento Base (2007, p. 57) disponível no potal do Ministério da Educação, estabele as diretrizes que qualificam uma instituição de ensino para ofertar cursos na modalidade PROEJA.

Dessa forma, o Instituto Federal de Educação, Ci-

\footnotetext{
${ }^{1}$ Segundo Lima (2007), ansiedade matemática é o medo que algumas pessoas têm da matemática. É a tentativa de aprender um assunto sem estar preparado para ele.
}

ência e Tecnologia do Tocantins (IFTO) se credencia a ministrar Educação Profissional Integrada ao Ensino Médio na modalidade de PROEJA. De acordo com a Organização Didática Pedagógica do PROEJA no Campus Palmas, a organização curricular consolidada no projeto de cursos de educação profissional de nível médio na modalidade de educação de jovens e adultos obedece ao disposto na Resolução CBE/CBE n. 1, de 5 de julho de 2000, que estabelece as Diretrizes Curriculares Nacionais para e Educação de Jovens e Adultos, no Decreto n. 5.840, de 13 julho de 2006, e na legislação complementar expedida pelos órgãos competentes. A organização curricular dos cursos conduz o aluno a uma habilitação profissional de nível médio que também lhe dará o direito à continuidade de estudos na educação superior.

Para o desenvolvimento da metodologia proposta no tema deste trabalho utilizamos, a título de exemplo, a função quadrática. O estudo de funções é um assunto de grande impotância na matemática e, de acordo com as Orientações Educacionais Complementares aos Parâmetros Curriculares (PCN+), (BRASIL, 2000, p. 121).

De acordo com a Resolução ${ }^{\circ}$ 002/2010 do Conselho Superior do IFTO, o profissional qualificado em manutenção e operação de microcomputadores tem por características e perfil a capacidade de compreender manuais técnicos, configurar um computador, instalar softwares computacionais, operá-los, entre outras características.

O winplot é um software matemático, desenvolvido por Richard Parris da Phillips Exeter Academy, em New Hampshire - EUA. É um software livre, não requer o pagamento por sua licença, que constrói gráficos de funções matemáticas em 2D (duas dimensões) e 3D (três dimensões), tornando-se, assim, um grande aliado do professor no processo de ensino e de aprendizagem em matemática.

É importante que o usuário tenha domínio na operacionalização e conhecimento dos recursos disponíveis no software. Usado de forma adequada, o computador torna-se um importante aliado do professor nas aulas de matemática. Fazer o esboço de gráficos de funções quadráticas pelo método tradicional, em geral, costuma ser trabalhoso para o professor e também para os alunos. Com o auxílio do software winplot, estima-se que as construções sejam mais rápidas e precisas.

Com o auxílio do computador e do software winplot, o trabalho sugere uma série de atividades para o ensino de funções quadráticas nas turmas do PROEJA, tendo como objetivo principal apresentar ao professor e ao aluno um texto de fácil compreensão e com atividades que descrevam passo-a-passo a construção do gráfico de uma família de funções quadráticas.

Em cada atividade, serão explorados alguns recursos disponíveis no software com o intuito de agilizar as construções gráficas, apresentando ao usuário uma solução não apenas do ponto de vista algébrico, mas também 
geométrico. De acordo com Giraldo (2012), o papel fundamental do computador é o de motivar conjecturas e indicar caminhos para a solução do problema e para a generalização desta solução, além de enriquecer a compreensão desta solução por meio da articulação entre as representações algébrica e gráfica.

Pretende-se também explorar os recursos gráficos disponíveis no software, variando-se os parâmetros de uma mesma função pré-definida e analisando-se as relações entre o gráfico de uma função quadrática e os seus respectivos coeficientes (parâmetros).

Esse artigo está estruturado em duas seções, além da introdutória. Nas seções 2 e 3, propõem-se cinco atividades práticas, com o auxílio do software winplot, em que o leitor é levado a seguir uma série de comandos com o objetivo de construir gráficos de funções quadráticas e avaliar o comportamento deles em relação às variações de seus parâmetros. A quinta atividade é uma aplicação do conceito de valor máximo e valor mínimo de uma função quadrática a uma situação hipotética referente a receita máxima obtida com a venda de refeições no restaurante do IFTO - Campus Palmas. As considerações finais são colocadas no seção 4 .

\section{Propostas de atividades para o en- sino de funções quadráticas}

\subsection{Relação entre a variação dos coeficientes e o comportamento do gráfico de uma função quadrática}

Nessa seção, serão apresentadas algumas atividades com o objetivo de investigar o comportamento do gráfico de uma função quadrática em relação à variação dos coeficientes $a, b$ e $c$, também chamados de parâmetros da função quadrática $f(x)=a x^{2}+b x+c$. Pretende-se com o auxílio do software winplot construir gráficos de funções quadráticas, buscando maior precisão e agilidade nas construções.

Será indicada em todas as atividades a sequência de comandos necessária para a realização da atividade em questão.

\subsection{Variação no Parâmetro $a$}

Atividade 1. Construa o gráfico da família de funções quadráticas $f: \mathbb{R} \rightarrow \mathbb{R}$ do tipo $f(x)=a x^{2}+b x+c, \forall a \in$ $\mathbb{Z}, b \in \mathbb{R}, c \in \mathbb{R}$ e $-4<a<4$.

\section{Objetivos da atividade}

- Avaliar o comportamento do gráfico da função quadrática em relação às variações no parâmetro a.
- Usar o recurso de animações de gráficos disponibilizado no winplot, por meio da opção Anim, para avaliar a concavidade e a abertura do gráfico da função quadrática.

- Plotar em um mesmo sistema de coordenadas cartesianas diversos gráficos de funções quadráticas.

- Apresentar uma justificativa geométrica, por meio do comando Anim, do pôrque o parâmetro $a$ da função quadrática ser definido para valores de $a \neq 0$. Uma justificativa formal será apresentada no final dessa atividade.

Procedimento para construção do gráfico no winplot

$\left.1^{\circ}\right)$ Use os comandos de acordo com a sequência: Janela $\longrightarrow$ 2-dim $\longrightarrow$ Equação $\longrightarrow$ Explícita.

$\left.2^{\circ}\right)$ Digite na caixa de texto o trinômio $a x^{2}+b x+c$ e clique no botão ok, conforme indicado na a Figura 1.

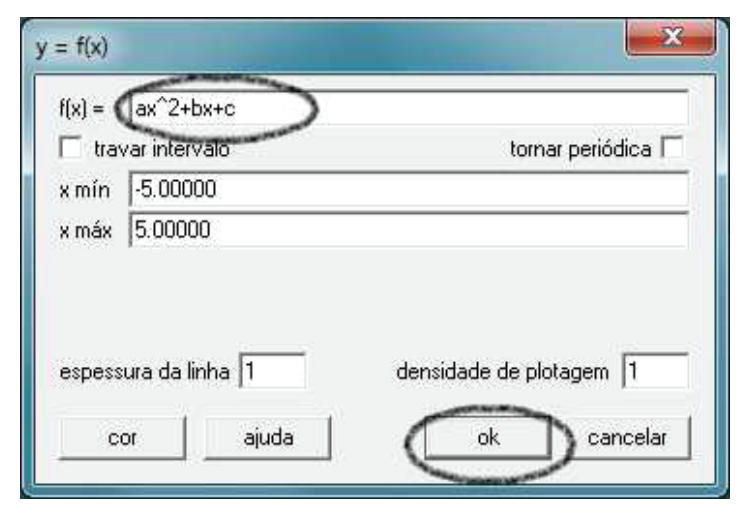

Figura 1: Caixa de texto

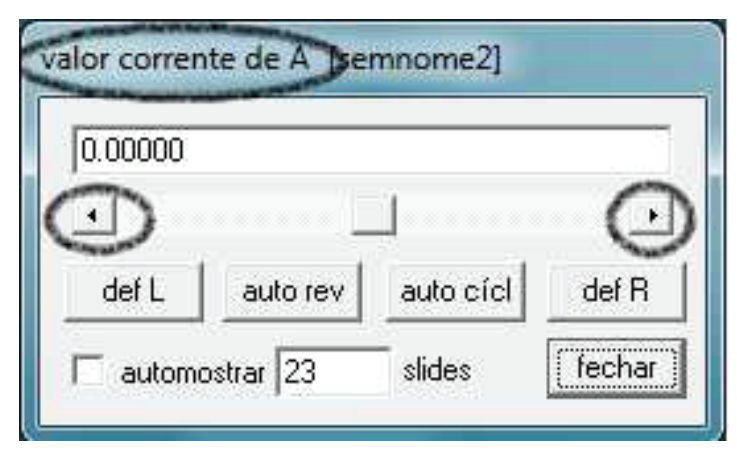

Figura 2: Caixa de comandos

$3^{\circ}$ ) Um recurso disponível no software que pode ser muito útil nas observações e na possibilidade do 
usuário arbitrariamente escolher os valores dos parâmetros é a animação de gráficos. Esse recurso pode ser utilizado por meio da opção Anim. Clique nesse botão e, em seguida, no botão Individuais. Escolha a opção B. Vai aparecer uma caixa de comandos em que o usuário deverá clicar nas setas que estão nas extremidade e fixar um valor arbitrário para $B$.

$4^{\mathrm{o})}$ Clique novamente no botão Anim seguido da opção Individuais e escolha o parâmetro $C$. Use as setas que estão nas extremidades e fixe um valor arbitrário.

$5^{\circ}$ ) Conforme ilustrado na Figura 3, o gráfico obtido é semelhante a uma reta. A justificativa para o fato é porque o parâmetro $a$ fica definido inicialmente como igual a zero, como pode ser observado na Figura 2 e, portanto, não define um função quadrática. Dessa forma, é necessário usar novamente o comando Anim para atribuir valores para $a$. Use esse comando para variar o parâmetro $a$ e observar o comportamento do gráfico para valores positivos, negativos e próximos de zero. Geometricamente, é possível ilustrar ao aluno que, aproximando-se os valores de $a$ de zero, o gráfico aproxima-se de uma reta. Em seguida, feche a caixa de comandos.

$\left.6^{\circ}\right)$ Na caixa de comandos inventário, o software disponibiliza alguns recursos para edição da função e do gráfico. Clique na opção editar e substitua o valor do coeficiente $a$ para valores $-4<a<4$, conforme o enunciado da atividade 1 e indicado na Figura 4.

$7^{\circ}$ ) Procure no ambiente inventário a opção nome. Clique nesse botão e dê o nome à função de acordo com a cor do gráfico.

$8^{\circ}$ ) Em um mesmo sistema de coordenadas cartesianas, clique na opção equação seguido da opção explícita. Digite novamente o trinomio $a x^{2}+b x+c$ substituindo o coeficiente $a$ por um novo valor, de modo que $-4<a<4$. Para cada novo trinômio, repita os procedimentos desse item substituindo $a$ pelos demais valores $-4<a<4$.

$\left.9^{\circ}\right)$ A Figura 5 representa os gráficos das funções quadráticas para valores de $a \in \mathbb{Z}, b \in \mathbb{R}, c \in \mathbb{R}$ e $-4<a<4$. Observe os gráficos e estabeleça uma relação entre as variações no parâmetro $a$ com a abertura e concavidade das parábolas.

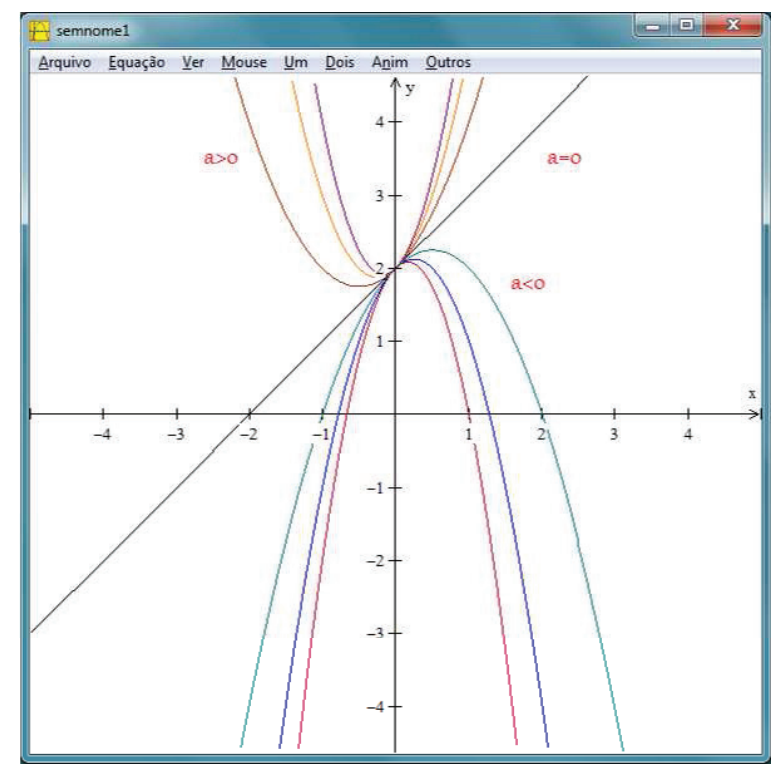

Figura 5: Gráficos das funções quadráticas $f(x)=a x^{2}+$ $b x+c$ para valores $-4<a<4$

Resultados esperados: ao final dessa atividade, esperase que o aluno compreenda que o parâmetro $a$ é responsável pela concavidade e abertura do gráfico da função quadrática. Em relação à concavidade, consideram-se duas possibilidades: voltada para cima, para valores de $a>0$, ou voltada para baixo, para valores de $a<0$. Em relação à abertura do gráfico, quanto maior o valor absoluto de $a$, menor será a sua abertura.

Uma justificativa matemática: nessa atividade, foi explorado o uso de diversos comandos com o objetivo de conjecturar algumas relações entre o parâmetro $a$ e o comportamento do gráfico. Essas relações podem ser justificadas, formalmente, como segue.

\section{Em relação à abertura da parábola}

Dada a função quadrática $f(x)=a x^{2}+b x+c$ e a reta $y=c$, os valores de $x$ tais que $f(x)=y$ são:

$a x^{2}+b x+c=c \Rightarrow$

$a x^{2}+b x=0 \Rightarrow$

$x(a x+b)=0 \Rightarrow$

$x_{1}=0$ ou $x_{2}=-b / a$

Portanto, $d\left(x_{1}, x_{2}\right)=\left|-\frac{b}{a}-0\right|=\left|-\frac{b}{a}\right|$.

Dessa forma, $d\left(x_{1}, x_{2}\right)$ é inversamente proporcional ao parâmetro $a$, ou seja, quanto maior o valor de $a$, em módulo, menor será $d\left(x_{1}, x_{2}\right)$ e, consequentemente, menor será a abertura do gráfico. Reciprocamente, quando menor o valor de $a$, em módulo, maior será a abertura do gráfico. 


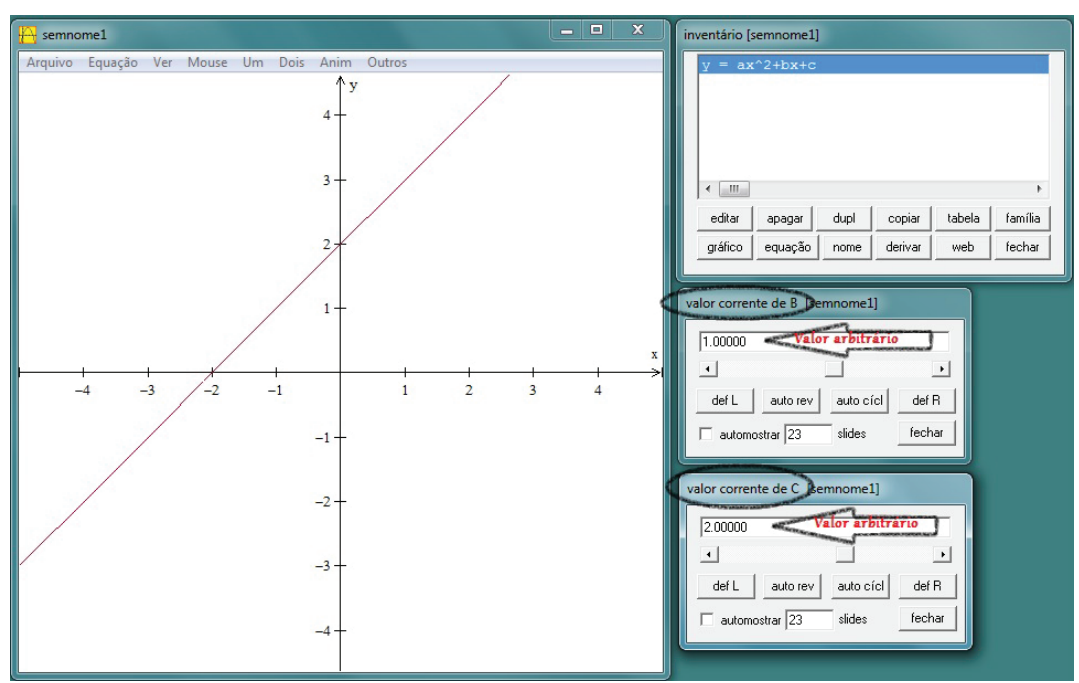

Figura 3: Valores arbitrários para os parâmetros $b$ e $c$
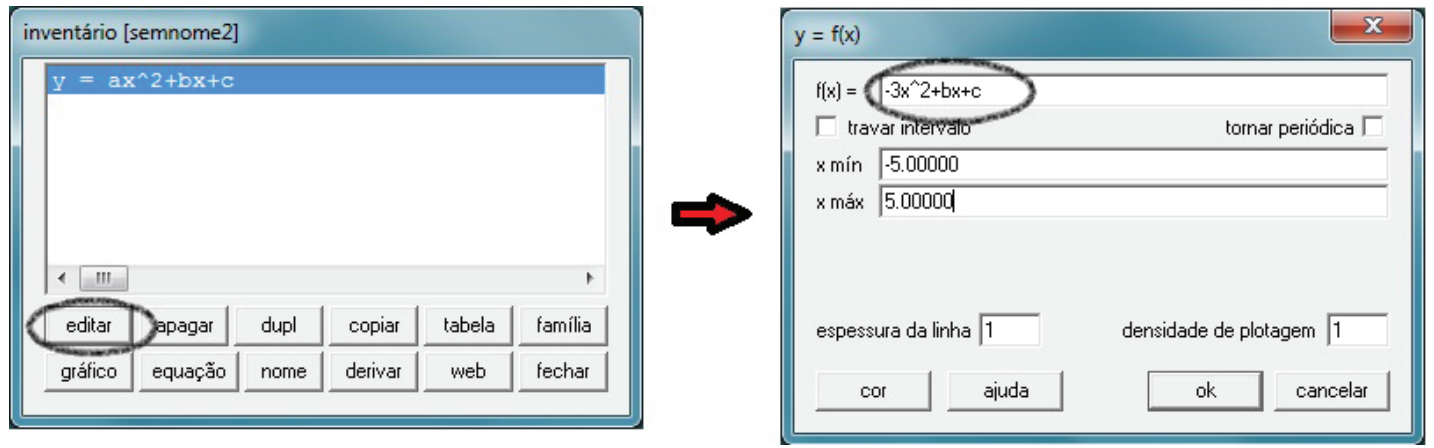

Figura 4: Inventário

Em relação à concavidade da parábola

A partir da forma canônica de uma função quadrática, podem-se determinar os valores de $f(x)=y$. Tomemos inicialmente a função na forma canônica:

$f(x)=a\left[\left(x+\frac{b}{2 a}\right)^{2}-\frac{\triangle}{4 a^{2}}\right] \Rightarrow f(x)=a\left(x+\frac{b}{2 a}\right)^{2}-\frac{\triangle}{4 a}$.

Como $\left(x+\frac{b}{2 a}\right)^{2}$ é sempre positivo para todo $x \in \mathbb{R}$, têm-se dois casos a considerar:

$1^{\circ}$ caso: $a>0$

Dessa forma, $a\left(x+\frac{b}{2 a}\right)^{2} \geq 0$ e, portanto:

$$
y=a\left(x+\frac{b}{2 a}\right)^{2}-\frac{\triangle}{4 a} \geq-\frac{\triangle}{4 a}=y_{v} .
$$

Dessa forma, a função assumirá valores sempre maiores ou iguais ao valor mínimo da função $\left(y_{v}\right)$. Portanto, o gráfico da função terá concavidade voltada para cima.

\section{$2^{\circ}$ caso: $a<0$}

Nesse caso, $a\left(x+\frac{b}{2 a}\right)^{2} \leq 0$ e, portanto:

$$
y=a\left(x+\frac{b}{2 a}\right)^{2}-\frac{\triangle}{4 a} \leq-\frac{\triangle}{4 a}=y_{v} .
$$

Nesse caso, a função assumirá valores sempre menores do que ou igual ao valor máximo da função $\left(y_{v}\right)$. Portanto, o gráfico da função terá concavidade voltada para baixo.

\subsection{Variação no Parâmetro $b$}

Atividade 2. Utilizando o winplot construa em um mesmo sistema de coordenadas cartesianas os gráficos das funções $f: \mathbb{R} \rightarrow \mathbb{R}$ definida como $f(x)=$ $x^{2}+b x+1$ para $-4<b<4$ e $b \in \mathbb{Z}$.

\section{Objetivos da atividade}

- Com o auxílio do winplot, analisar o comportamento do gráfico da função quadrática. 
- Fixados os valores dos parâmetros $a$ e $c$, conjecturar a influência do parâmetro $b$ sobre o comportamento do gráfico.

- Estabelecer uma relação entre o parâmetro $b$ e as coordenadas do vértice do gráfico da função quadrática.

\section{Procedimento para construção do gráfico no win- plot}

$1^{\circ}$ ) Use os comandos de acordo com a sequência: Janela $\longrightarrow$ 2-dim $\longrightarrow$ Equação $\longrightarrow$ Explícita.

$2^{\circ}$ ) Digite na caixa de texto o trinômio $x^{2}+b x+1 \mathrm{e}$ clique em no botão $o k$.

$3^{\circ}$ ) Em seguida, use a ferramenta Anim para fazer algumas animações do gráfico em função do parâmetro $b$. Para isso, deve-se clicar em: Anim $\rightarrow$ Individuais $\rightarrow B$. Vai aparecer uma caixa de comandos em que o usuário deverá clicar nas setas que estão nas extremidade para variar os valores do parâmetro $b$. Faça alguns testes e analise o comportamento da parábola para valores diferentes de $b$.

$\left.4^{\circ}\right)$ Após os testes preliminares, o objetivo agora é construir o gráfico das funções quadráticas definida no enunciado. Para isso, deve-se atribuir valores para $b$, tais que $-4<b<4$ e $b \in \mathbb{Z}$.

$\left.5^{\circ}\right)$ Na caixa de comandos inventário, conforme Figura 6, clique na opção editar e atribua -3 para o coeficiente $b$ da função $f(x)=x^{2}+b x+1$ definida no enunciado. Em seguida, clique em $o k$.

$\left.6^{\circ}\right)$ Para construir os demais gráficos, para valores de $-4<b<4$ e $b \in \mathbb{Z}$, em um mesmo plano cartesiano, devem-se seguir os seguintes comandos: Equação $\rightarrow$ Explícita. Digite na caixa de texto o trinômio $x^{2}-2 x+1$ e clique em $o k$. Repita os comandos desse item para os demais valores de $b$.

$7^{\circ}$ ) A Figura 7 ilustra os gráficos da função $f: \mathbb{R} \rightarrow \mathbb{R}$ definida como $f(x)=x^{2}+b x+1$ para $-4<b<4$ e $b \in \mathbb{Z}$. Observe o comportamento do gráfico no intervalo $-4<b<4$ e conjecture uma relação entre as variações no parâmetro $b$ em relação ao comportamento do gráfico para valores fixos de $a$ e $c$.

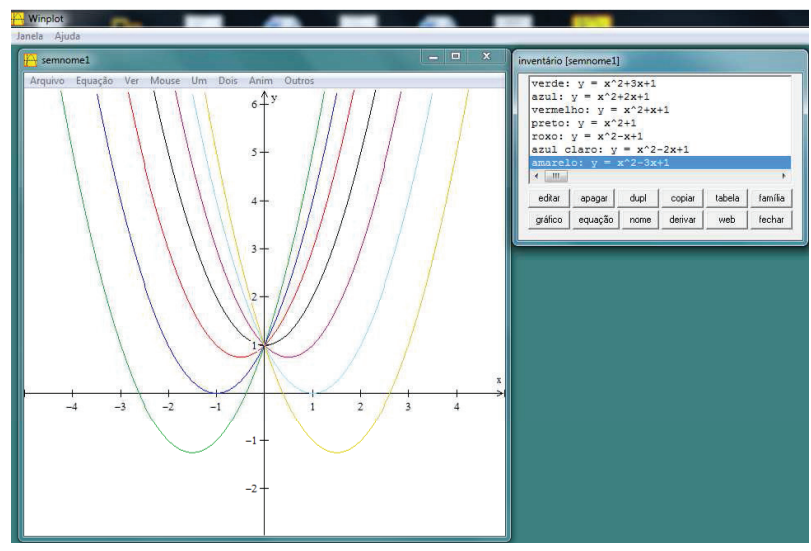

Figura 7: Variação no parâmetro $b$

Resultados esperados: espera-se que o aluno compreenda que a variação no parâmetro $b$ determina a posição do vértice, indicando se o ponto de intersecção do gráfico da função quadrática com o eixo das ordenadas ocorre em seu trecho crescente ou decrescente.

Uma justificativa matemática: a justificativa está nas coordenadas do vértice que estão em função de $b$, visto que $x_{v}=-\frac{b}{2 a}$ e $y_{v}=-\frac{b^{2}-4 a c}{4 a}$. No caso específico do $x_{v}$, podem-se analisar cinco casos:

$1^{0}$ caso

Para valores de $a>0$ e $b>0$, o $x_{v}=-\frac{b}{2 a}$ assumirá valores negativos e, consequentemente, o eixo de simetria do gráfico da função quadrática estará à esquerda do eixo das ordenadas. Dessa forma, conforme ilustra a Figura 8, o ponto de intersecção do gráfico com o eixo das ordenadas ocorre no trecho crescente do gráfico ou à direita do eixo de simetria.

\section{$2^{\circ}$ caso}

Para valores de $a>0$ e $b<0$, o $x_{v}=-\frac{b}{2 a}$ assumirá valores positivos e, consequentemente, o eixo de simetria do gráfico da função quadrática estará à direita do eixo das ordenadas. Dessa forma, conforme ilustra a Figura 9, o ponto de intersecção do gráfico com o eixo das ordenadas ocorrerá no trecho decrescente do gráfico. 

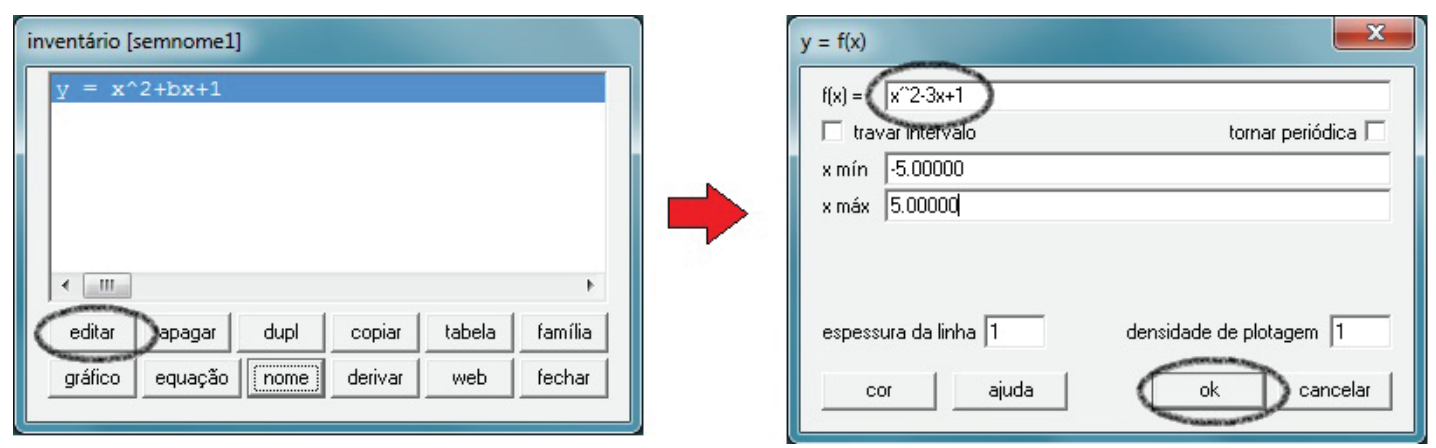

Figura 6: Representação dos comandos do item 5

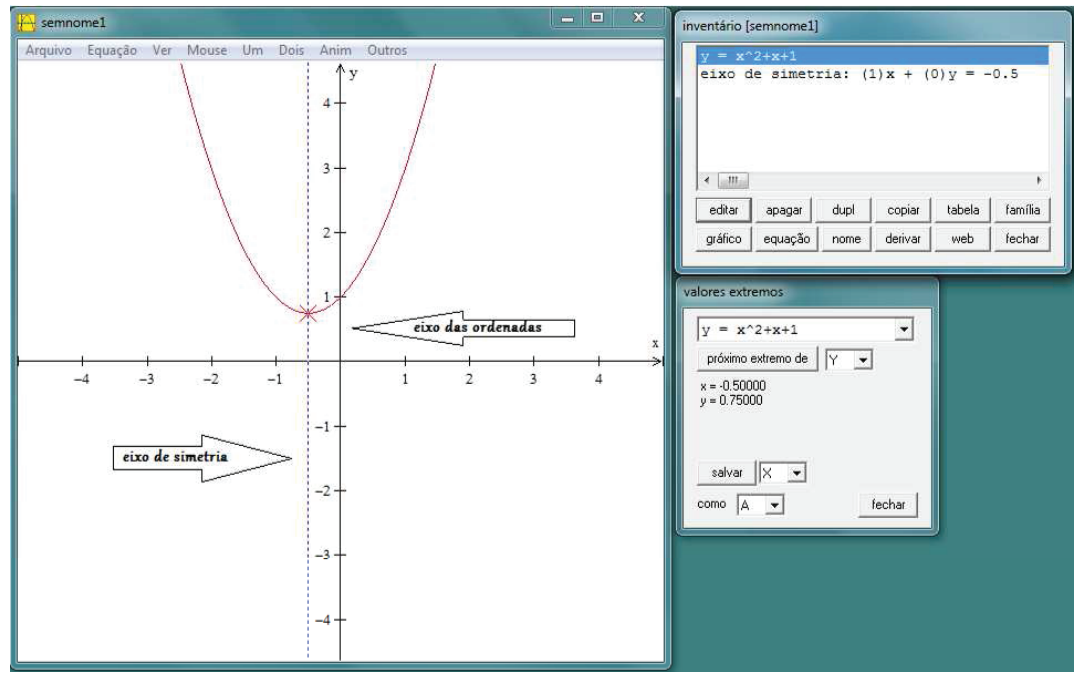

Figura 8: Gráfico da função quadrática $f(x)=x^{2}-x+1$ para valores de $a>0$ e $b>0$

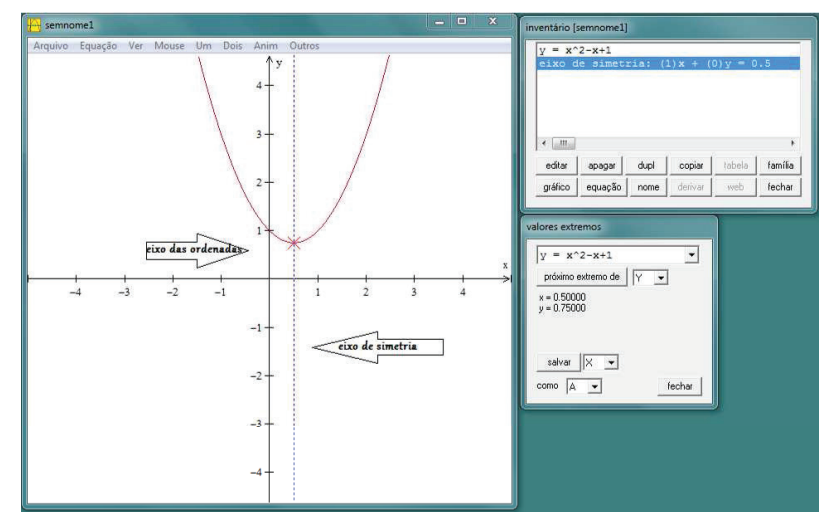

Figura 9: Gráfico da função quadrática $f(x)=x^{2}-x+1$ para valores de $a>0$ e $b<0$

\section{$3^{0}$ caso}

Para valores de $a<0$ e $b>0$, o $x_{v}=-\frac{b}{2 a}$ assumirá valores positivos e, consequentemente, o eixo de simetria do gráfico da função quadrática estará à direita do eixo das ordenadas. Dessa forma, conforme ilustra a Figura 10, o ponto de intersecção do gráfico com o eixo das ordenadas ocorrerá no trecho crescente do gráfico.

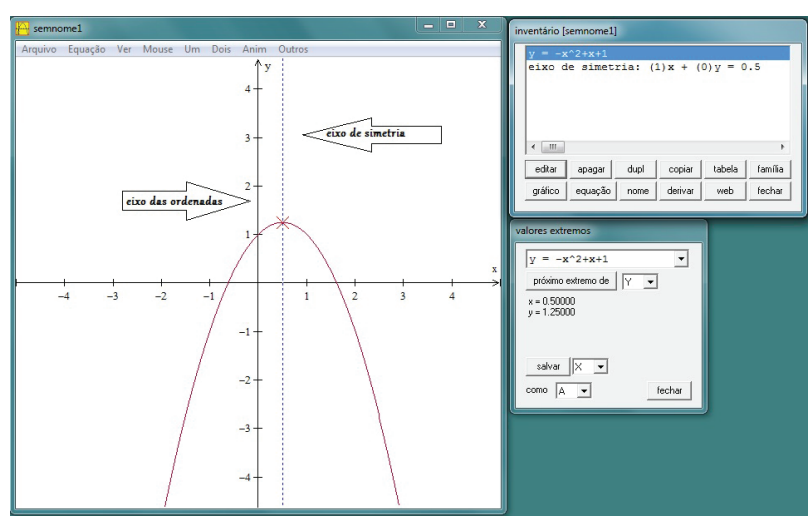

Figura 10: Gráfico da função quadrática $f(x)=-x^{2}+$ $x+1$ para valores de $a<0$ e $b>0$ 
$4^{\mathbf{o}}$ caso Para valores de $a<0$ e $b<0$, o $x_{v}=-\frac{b}{2 a}$ assumirá valores negativos e, consequentemente, o eixo de simetria do gráfico da função quadrática estará à esquerda do eixo das ordenadas. Dessa forma, conforme a ilustra Figura 11, o ponto de intersecção do gráfico com o eixo das ordenadas ocorrerá no trecho decrescente do gráfico.

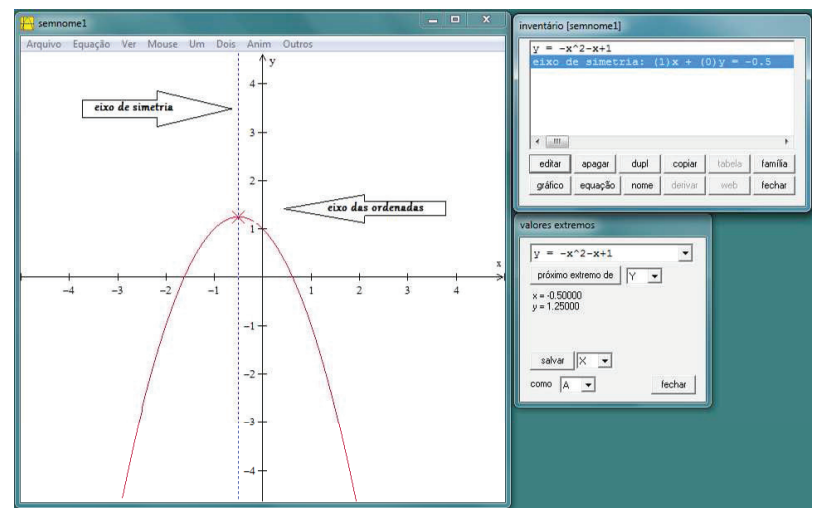

Figura 11: Gráfico da função quadrática $f(x)=-x^{2}-$ $x+1$ para valores de $a<0$ e $b<0$

$5^{\mathbf{0}}$ caso Para valores de $a \in \mathbb{R}-\{0\}$ e $b=0$, o $x_{v}=$ $-\frac{b}{2 a}$ sempre será igual a zero e, consequentemente, o eixo de simetria do gráfico da função quadrática coincidirá com eixo das ordenadas. Dessa forma, conforme ilustra a Figura 12, o ponto de intersecção do gráfico com o eixo das ordenadas será o próprio vértice.

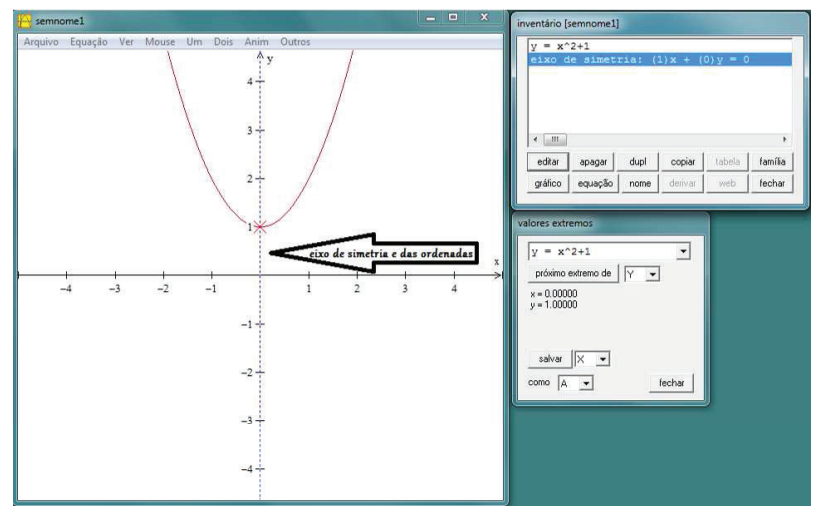

Figura 12: Gráfico da função quadrática $f(x)=x^{2}+1$ para valores de $a \in \mathbb{R}-\{0\}$ e $b=0$

Atividade 3. Intuitivamente pode-se conjucturar uma relação entre os vértices da família de funções $f: \mathbb{R} \rightarrow \mathbb{R}$ do tipo $f(x)=x^{2}+b x+1$ e $b \in \mathbb{Z}$ para $-4<b<4$. Que relação é essa?

\section{Objetivo da atividade}

- Marcar os vértices da cada parábola construída na atividade 2, a partir de seus valores extremos, com o objetivo de estimular o aluno a encontrar uma relação entre eles.

\section{Procedimento para determinar os vértices e construir o gráfico no winplot}

$\left.1^{\circ}\right)$ Use os comandos de acordo com a sequência: Janela $\longrightarrow$ 2-dim $\longrightarrow$ Equação $\longrightarrow$

$\left.2^{\circ}\right) \mathrm{O}$ winplot disponibiliza um recurso que fornece ao usuário os valores extremos $\left(x_{v}, y_{v}\right)$ do gráfico da função quadrática. Para usar esse recurso, devemse usar os seguintes comandos: $U m \rightarrow$ Extremos. A partir das sete parábolas construídas na Atividade 2 , determine os seus respectivos pontos extremos com o auxílio do software.

$\left.3^{\circ}\right)$ Selecione, com um clique simples, alguma das sete funções que aparecem na caixa de comandos inventário, conforme mostra a Figura 13.

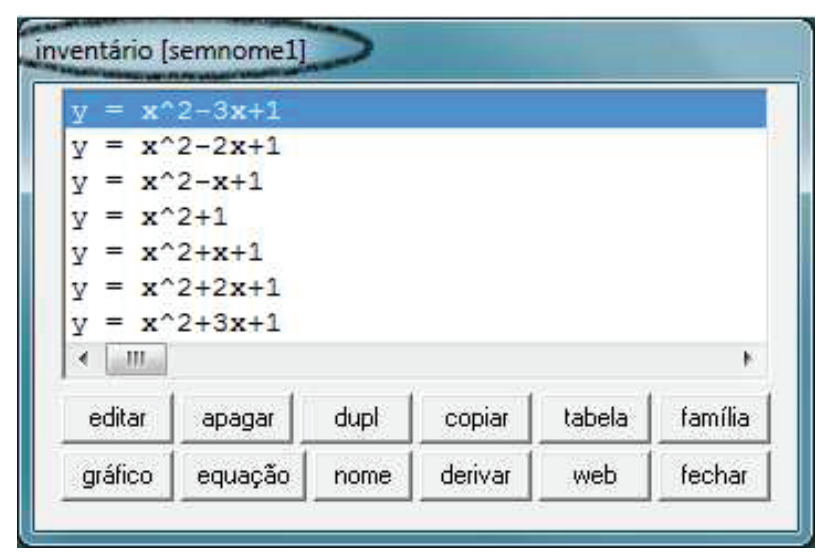

Figura 13: Caixa de comandos inventário

$4^{\mathrm{O}}$ ) O objetivo agora é determinar os valores extremos da função, também chamados de coordenadas do vértice $\left(x_{v}, y_{v}\right)$. Para isso, clique no botão Um seguido da opção Extremos, conforme ilustra a Figura 14. 


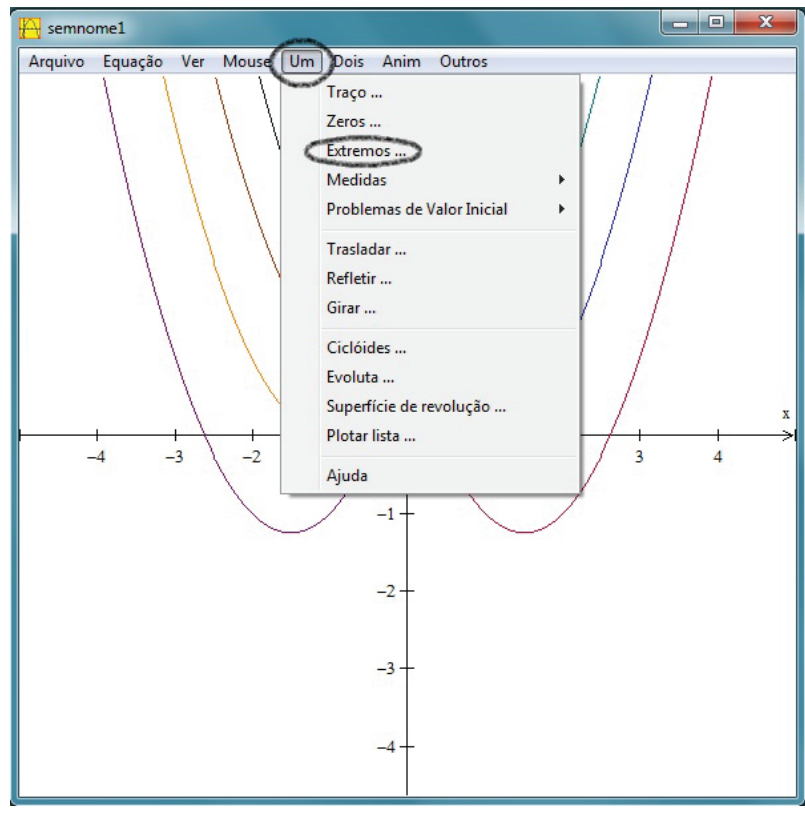

Figura 14: Visualização dos comandos $U m \rightarrow$ Extremos...

$5^{\circ}$ ) Após o comando anterior, vai aparecer uma nova caixa de comandos indicando os valores extremos da função selecionada no item 2, conforme indicado na Figura15. Com esses valores (coordenadas), pode-se marcar o ponto na parábola.

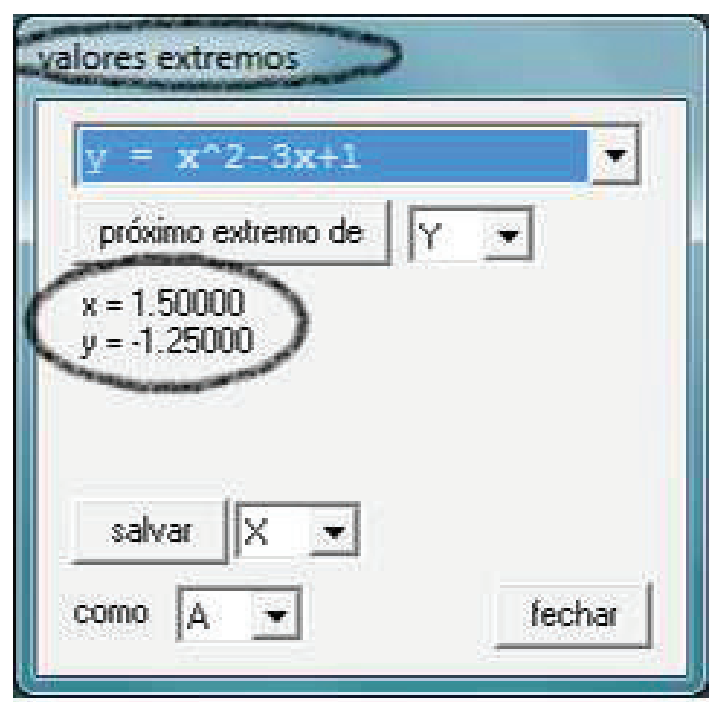

Figura 15: Visualização dos valores extremos

$\left.6^{\circ}\right)$ Para marcar o ponto na parábola, devem-se seguir os comandos: Equação $\rightarrow$ Ponto $\rightarrow(x, y)$. Vai aparecer uma nova caixa de comandos em que o usuário deve atribuir valores para $x$ e $y$ de acordo com os valores extremos obtidos no item 4 . Para uma melhor visualização do ponto, selecione nessa mesma caixa de comandos a opção sólido, conforme ilustra

\section{a Figura16.}

$\left.7^{\circ}\right)$ Clique na seta que aparece no canto superior da caixa de comandos Valores extremos e escolha outra função, conforme ilustra a Figura 17. Repita os passos descritos no item anterior para marcar os demais pontos extremos nas parábolas.

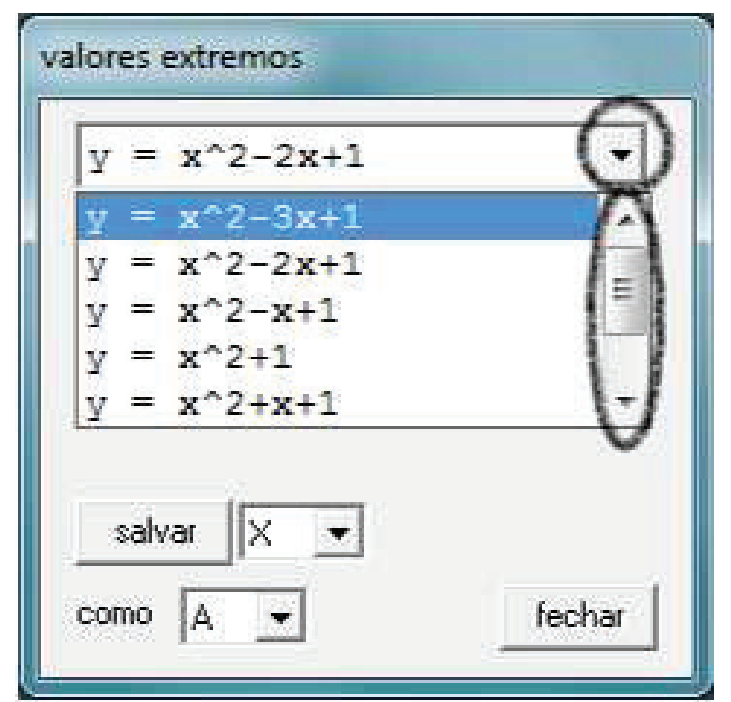

Figura 17: Visualização dos comandos descritos no item 6

$8^{\circ}$ ) Ao final de todas as etapas anteriores, obtém-se uma figura semelhante a Figura 18. Faça uma análise sobre a disposição dos sete pontos e tente conjecturar alguma relação entre eles.

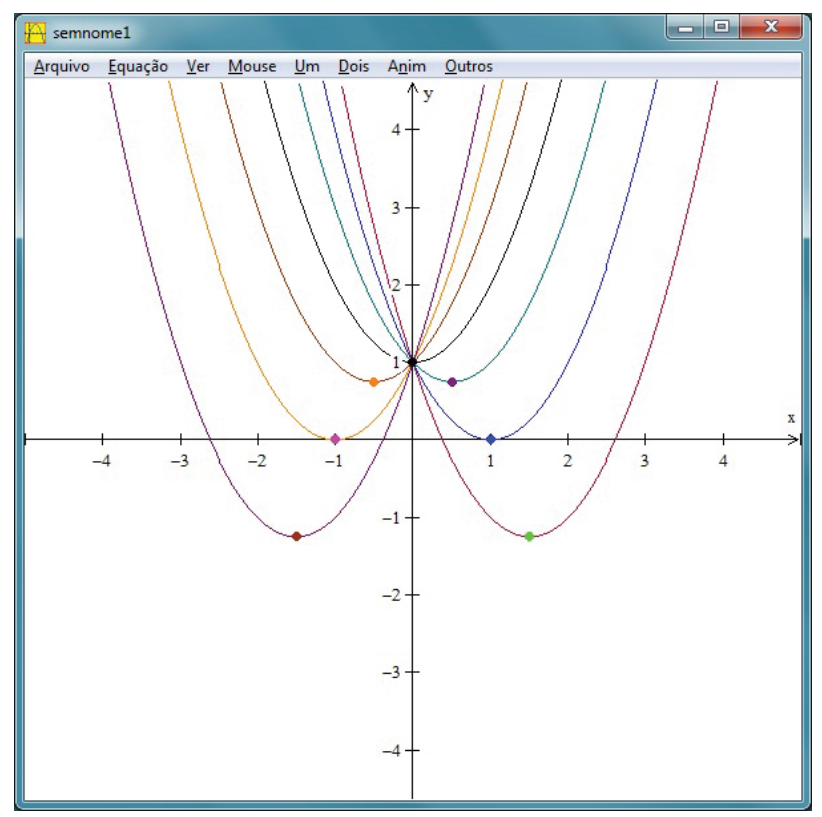

Figura 18: Pontos de extremos 


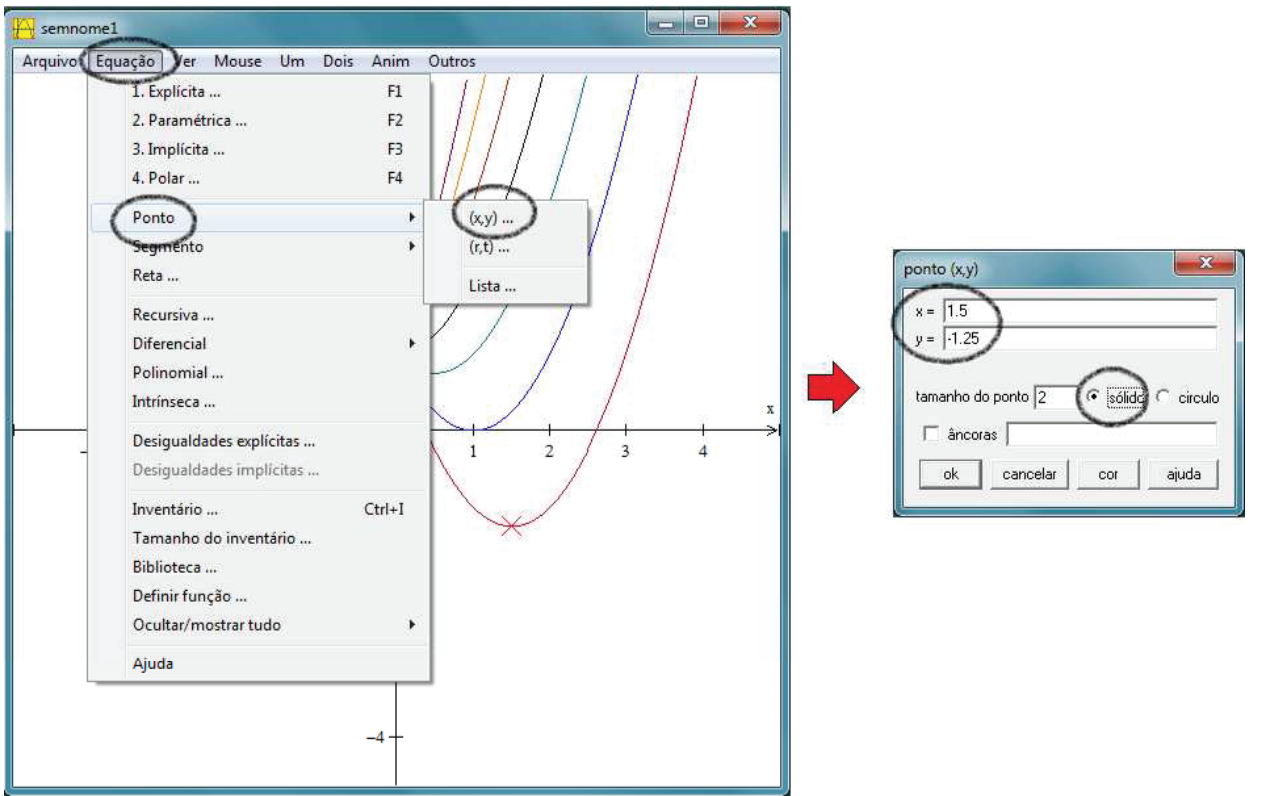

Figura 16: Visualização dos comandos descritos no item 5

$\left.9^{\circ}\right)$ Conhecendo-se as coordenadas de cada ponto extremo, é possível escolher arbitrariamente três deles, substituir na forma geral da função quadrática $f(x)=a x^{2}+b x+c$ e resolver um sistema de três equações e três variáveis $(a, b$ e $c)$. A solução desse sistema dá origem à função quadrática $g: \mathbb{R} \rightarrow \mathbb{R}$, definida por $g(x)=-x^{2}+1$. Substituindo-se os demais pontos extremos na função $g(x)=-x^{2}+1$, conclui-se que todos os sete pontos de extremos pertencem ao gráfico da função $g$.

$\left.10^{\circ}\right)$ A Figura 19 representa o gráfico da família de funções do tipo $f(x)=x^{2}+b x+1$ para $-4<b<4$ e o gráfico da função $g(x)=-x^{2}+1$.

A resposta da pergunta levantada na introdução da atividade 3 é que todo vértice do gráfico de uma família de funções $f: \mathbb{R} \rightarrow \mathbb{R}$ do tipo $f(x)=$ $a x^{2}+b x+c, a, b, c \in \mathbb{R}$ com $a$ e $c$ fixos, pertence ao gráfico da função $g: \mathbb{R} \rightarrow \mathbb{R}$ definida por $g(x)=-a x^{2}+c$. Uma justificativa para esse fato pode ser encontrada em Giraldo, Matos e Caetano $(2012)^{2}$ (cf. capítulo 3, p. 39).

\footnotetext{
${ }^{2}$ Material didático da disciplina Recursos Computacionais no Ensino Médio (MA36) do curso de Mestrado Profissional em Matemática em Rede Nacional (PROFMAT).
}

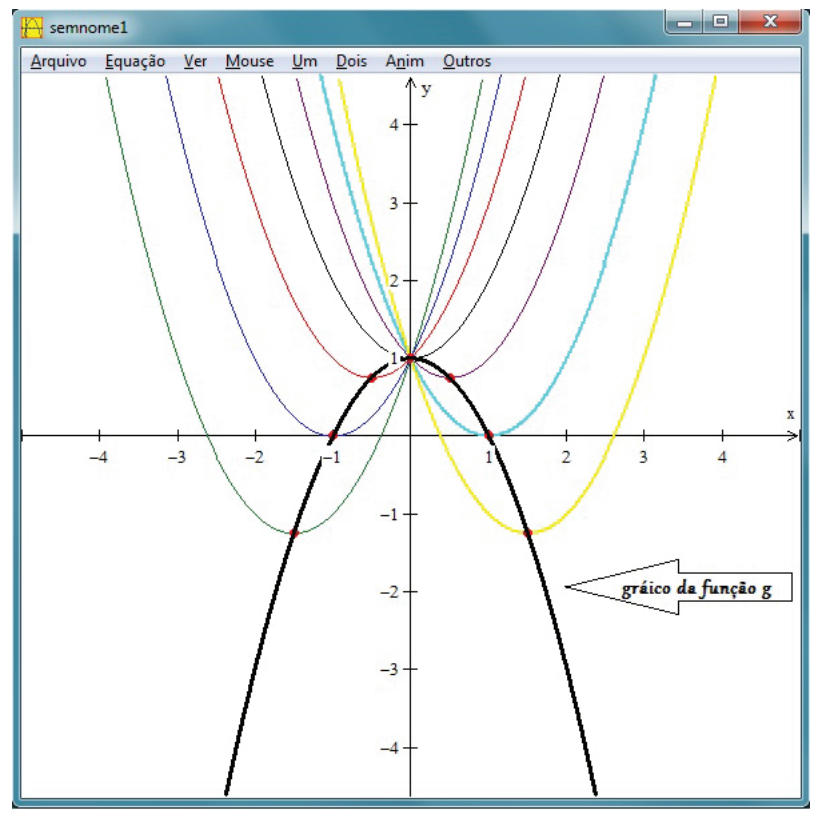

Figura 19: Gráfico da função $g: \mathbb{R} \rightarrow \mathbb{R}$ definida como $g(x)=-x^{2}+1$

\subsection{Variação no Parâmetro $c$}

Atividade 4. Dada uma função $f: \mathbb{R} \rightarrow \mathbb{R}$ do tipo $f(x)=x^{2}-4 x+c$, com $c \in \mathbb{Z}$, construa o gráfico das funções quadráticas para valores $-4<c<4$ e faça algumas considerações sobre o comportamento do gráfico em relação ao seu eixo de simetria.

Objetivos da atividade 
- Avaliar o comportamento do gráfico da função quadrática em relação às variações no parâmetro $c$.

- Observar a relação entre o parâmetro $c$ e o ponto de máximo $\left(x_{v}\right)$ do gráfico da função quadrática.

- Usar o recurso de animações de gráficos disponibilizado no winplot, por meio da opção Anim, para realizar algumas simulações em relação a variação no parâmetro $c$.

- Observar o comportamento do gráfico da função quadrática em relação ao seu eixo de simetria.

\section{Procedimento para construção do gráfico no winplot}

$\left.1^{\circ}\right)$ Use os comandos de acordo com a sequência: Janela $\longrightarrow$ 2-dim $\longrightarrow$ Equação $\longrightarrow$ Explícita.

$2^{\circ}$ ) Digite na caixa de texto o trinômio $x^{2}-4 x+c$ e clique no opção $o k$.

$\left.3^{\circ}\right) \mathrm{O}$ winplot disponibiliza um recurso muito útil que informa ao usuário os valores extremos (coordenadas do vértice) do gráfico da função quadrática. Para obter essas informações, efetue os comandos: $U m \rightarrow$ Extremos. A sequência de comandos gerará a janela observada na Figura 20

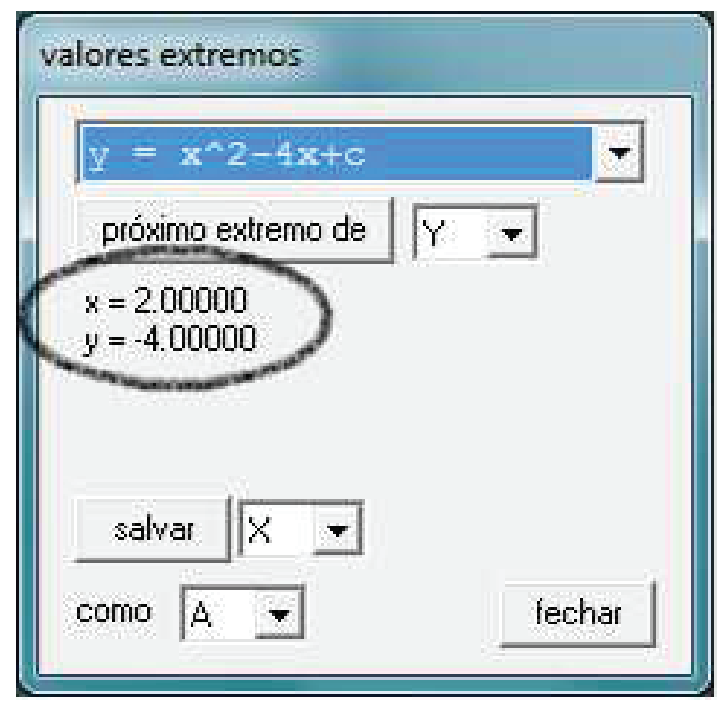

Figura 20: Valores extremos

$\left.4^{\circ}\right)$ Com as informações do $x_{v}=2$ e $y_{v}=-4$ da função $f(x)=x^{2}-4 x+c$, é possível obter o eixo de simetria (reta $x=-\frac{b}{2 a}$ ). Para isso, devem-se efetuar os seguintes comandos: Equação $\rightarrow$ Reta. Digite na caixa de texto os valores para os coefientes $a, b$ e $c$ de acordo com os dados representados na Figura 21.

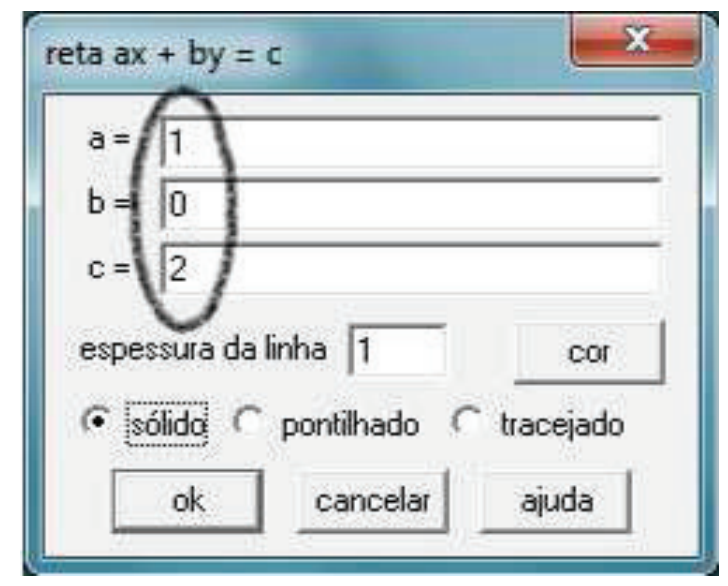

Figura 21: Coeficientes da equação da reta

$5^{\circ}$ ) O eixo simetria do gráfico da função $f(x)=x^{2}-$ $4 x+c$ é a reta $x=2$, coordenada do $x_{v}$. Observase tal fato na representação da Figura 22

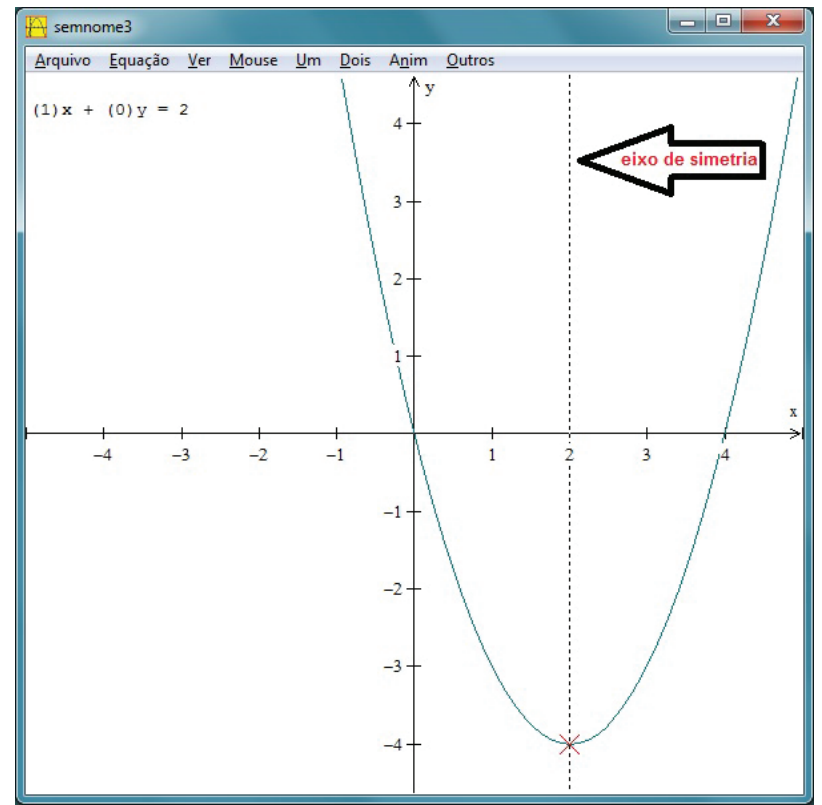

Figura 22: Representação do eixo de simetria

$\left.6^{\circ}\right)$ Para realizar algumas simulações do comportamento do gráfico para valores distintos do parâmetro $c$, pode-se utilizar o recurso de animações de acordo com os comandos: Anim $\longrightarrow$ Individuais $\longrightarrow$ C. Vai aparecer uma caixa de comandos em que o usuário deverá clicar nas setas que estão nas extremidade.

$\left.7^{\circ}\right)$ Para plotar os gráficos da função $f(x)=x^{2}-4 x+$ $c$ para valores de $-4<c<4$, deve-se prosseguir como: Janela $\longrightarrow$ 2-dim $\longrightarrow$ Equação $\longrightarrow$ Explícita. Digite o trinômio $x^{2}-4 x+4$ e clique em $o k$. Procure no ambiente inventário a opção nome. Note-se 
que esse procedimento é ilustrado por meio da Figura 23. Clique nesse botão e dê o nome à função de acordo com a cor do gráfico.

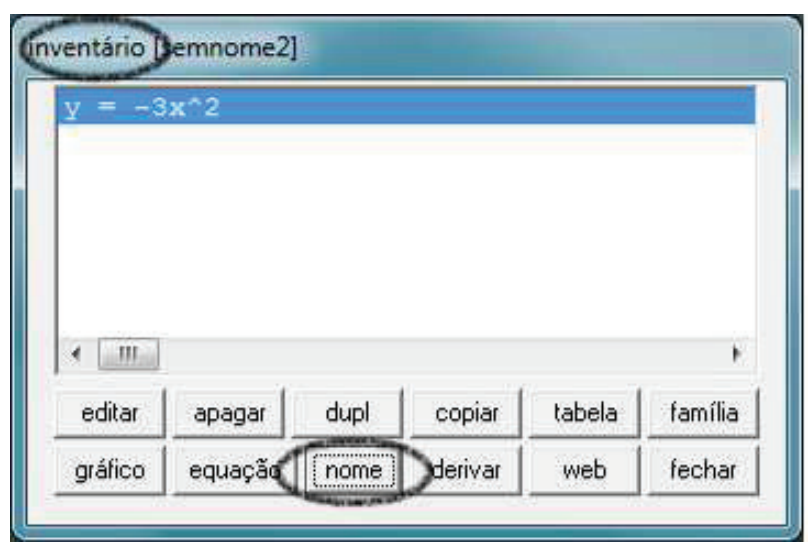

Figura 23: Inventário

$\left.8^{\circ}\right)$ Em um mesmo sistema de coordenadas cartesianas, clique nas opções Equação $\longrightarrow$ Explícita e repita os comandos do item anterior para os demais valores de $-4<c<4$. Para cada novo gráfico, escolha uma nova cor para diferenciar dos anteriores.

Resultados esperados: espera-se que o aluno visualize que o parâmetro $c$ indica o ponto onde o gráfico da função quadrática intersecta o eixo das ordenadas $(y)$ e, que associe isso ao fato de que $f(0)=c$. Que perceba o fato de que para valores de $a$ e $b$ fixos, o deslocamente do $x_{v}$ ocorre ao longo do eixo de simetria, de forma que o valor máximo ou mínimo da função ocorre para um determinado $y_{v}$. Por fim, espera-se que o estudante perceba o deslocamento do vértice sobre o eixo de simetria acontece porque o valor de $x_{v}=-\frac{b}{2 a}$ não depende de $c$. Para valores de $a$ e $b$ fixos e $c \in \mathbb{R}$, o $x_{v}$ permanece o mesmo, mudando apenas os valores de $y_{v}$, conforme ilustra a Figura 24.

\section{Aplicações das funções quadráti- cas}

Há determinados problemas do nosso dia a dia que podem ser representados por meio de uma equação ou de uma função. No caso específico das funções quadráticas, pode-se usar o processo de modelagem matemática ${ }^{3}$ para resolvê-los e interpretar os resultados. Com o auxílio do winplot, pode-se determinar os zeros e os valores extremos de uma função quadrática.

\footnotetext{
${ }^{3}$ Segundo Bassanezi (2009, p. 16), "modelagem matemática consiste na arte de transformar problemas da realidade em problemas matemáticos e resolvê-los interpretando suas soluções na linguagem do mundo real".
}

Atividade 5 (Receita Máxima). As refeições do restaurante acadêmico do IFTO - Campus Palmas são vendidas por 5 reais para servidores. Por dia o restaurante atrai em média 40 servidores. Se o preço das refeições aumenta 1 real ocorre uma redução de 10 clientes que são servidores e, inversamente, a redução do preço da refeição em 1 real provoca um aumento de 10 servidores no rol de clientes do restaurante. Isso se dá em função da concorrência de restaurantes próximos ao câmpus. O problema que se apresenta ao detentor da concessão do restaurante acadêmico é: qual deve ser o preço das refeições para que a receita seja máxima?

\section{Uma Solução algébrica}

Considere $R$ : a receita obtida em um dia de funcionamento do restaurante; $n r$ : o número de refeições servidas por dia e, vr: o valor de cada refeição.Dessa forma $R=(n r) \cdot(v r)$

Seja $x$ o valor correspondente à variação do preço da refeição para mais ou menos. Tem-se que $n r=40-10 x$ e $v r=5+x$.

Daí:

$$
\begin{aligned}
R(x) & =(40-10 x)(5+x) \\
& =200+40 x-50 x-10 x^{2} \\
& =-10 x^{2}-10 x+200 .
\end{aligned}
$$

O modelo matemático para esse problema é uma função quadrática em que a receita é função de $x$ e, portanto, a receita máxima ocorre para um determinado $x_{v}=-\frac{b}{2 a}$.

Daí:

$$
\begin{aligned}
x_{v} & =-\frac{(-10)}{2(-10)} \\
& =\frac{10}{-20} \\
& =-0,5 .
\end{aligned}
$$

Dessa forma, a receita máxima ocorre quando houver uma redução de 0,50 centavos no preço da refeição. Portanto, a receita máxima é dada pela expressão $=y_{v}=-10(-0,5)^{2}-10(-0,5)+200 \Rightarrow y_{v}=202,50$ reais.

\section{Solução geométrica}

Um vez obtido o modelo matemático para o problema, nesse caso, uma função quadrática, pode-se, com o auxílio de winplot, plotar o gráfico e calcular os valores extremos da função.

\section{Procedimento para construção do gráfico no win-} plot

$\left.1^{\circ}\right)$ Use os comandos: Janela $\longrightarrow$ 2-dim $\longrightarrow$ Equação $\longrightarrow$ Explícita. 


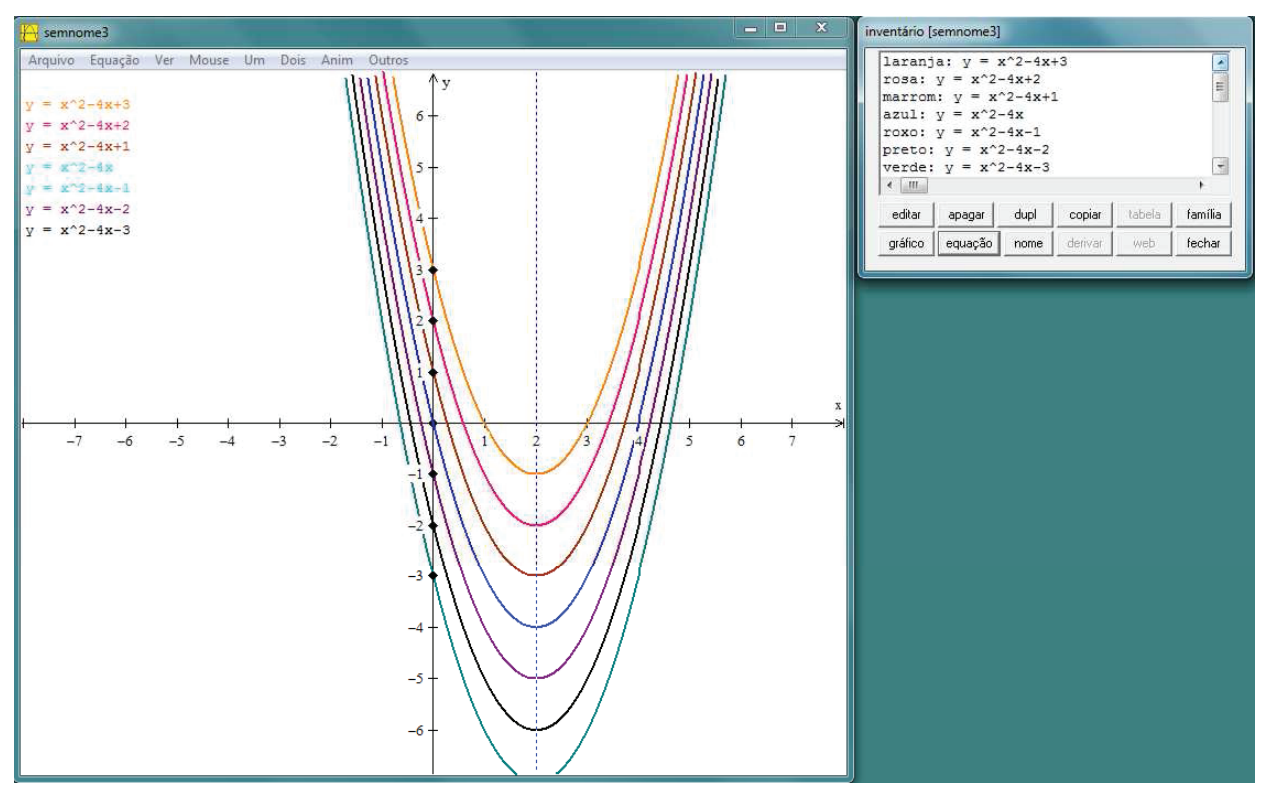

Figura 24: Representação gráfica das funções do tipo $f(x)=x^{2}-4 x+c$ para $-4<c<4$

$\left.2^{\circ}\right)$ Digite o trinômio obtido no modelo matemático: $-10 x^{2}-10 x+200$ e clique em ok. O gráfico que será plotado ficará distorcido por conta da escala. O ponto de intersecção com o eixo das ordenadas ocorre para $y=200$.

$3^{\circ}$ ) Outra ferramenta muito útil disponível no software é a opção Zeros. Por meio dessa opção, é possível determinar os zeros da função $R(x)=-10 x^{2}-$ $10 x+200$. Para determiná-los, clique na opção Um e em seguida na opção Zeros. Para encontrar o outro zero da função (se houver), clique na opção próximo, conforme ilustra a Figura 25.

$4^{\circ}$ ) Para uma melhor visualização do gráfico construído no item 2, clique na opção Ver em seguida clique novamente na opção Ver... . Marque a opção canto e preencha as opções (esquerdo, direito, inferior e superior). Em seguida, clique em aplicar. A escolha desses dados deve-se ao pontos notáveis já conhecidos.

$\left.5^{\circ}\right)$ Para determinar os valores extremos $\left(x_{v}, y_{v}\right)$ da função $R(x)=-10 x^{2}-10 x+200$, devem-se usar os comandos: $U m \longrightarrow$ Extremos. O uso desses comandos gerará uma janela como a da Figura 26

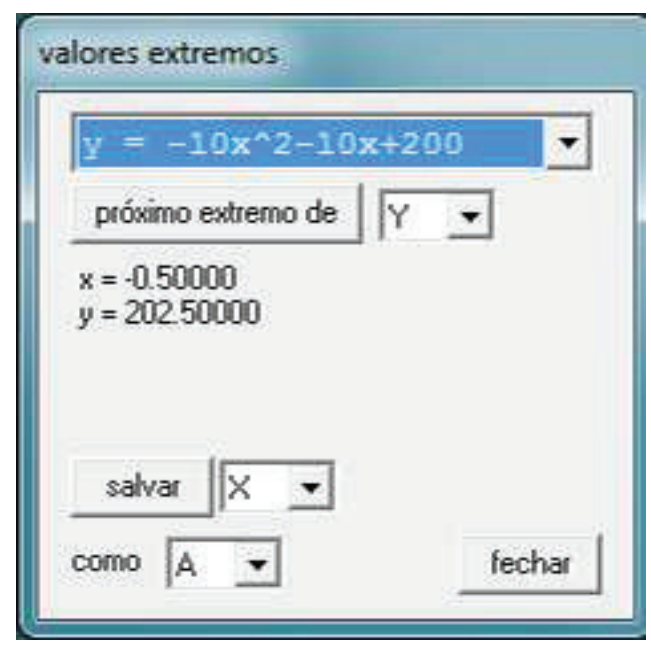

Figura 26: Valores extremos da função $R(x)=-10 x^{2}-$ $10 x+200$

$6^{\mathrm{O}}$ ) É possível também determinar o ponto de intersecção do gráfico com o eixo das ordenadas. Para obtê-lo, clique na opção Um, seguido da opção Traço. Marque $x=0$. Por meio da Figura 27 é ilustrado o gráfico da função $R(x)=-10 x^{2}-10 x+$ 200 após a execução de todos os comandos. O usuário tem ainda a opção de nomear os eixos de acordo com as variáveis envolvidas no problema. Para isso, clique na opção: Ver $\rightarrow$ Eixos $\rightarrow$ Nome.

\section{Avaliação do resultado em função dos parâmetros}

A Receita Máxima foi calculada a partir do produto 


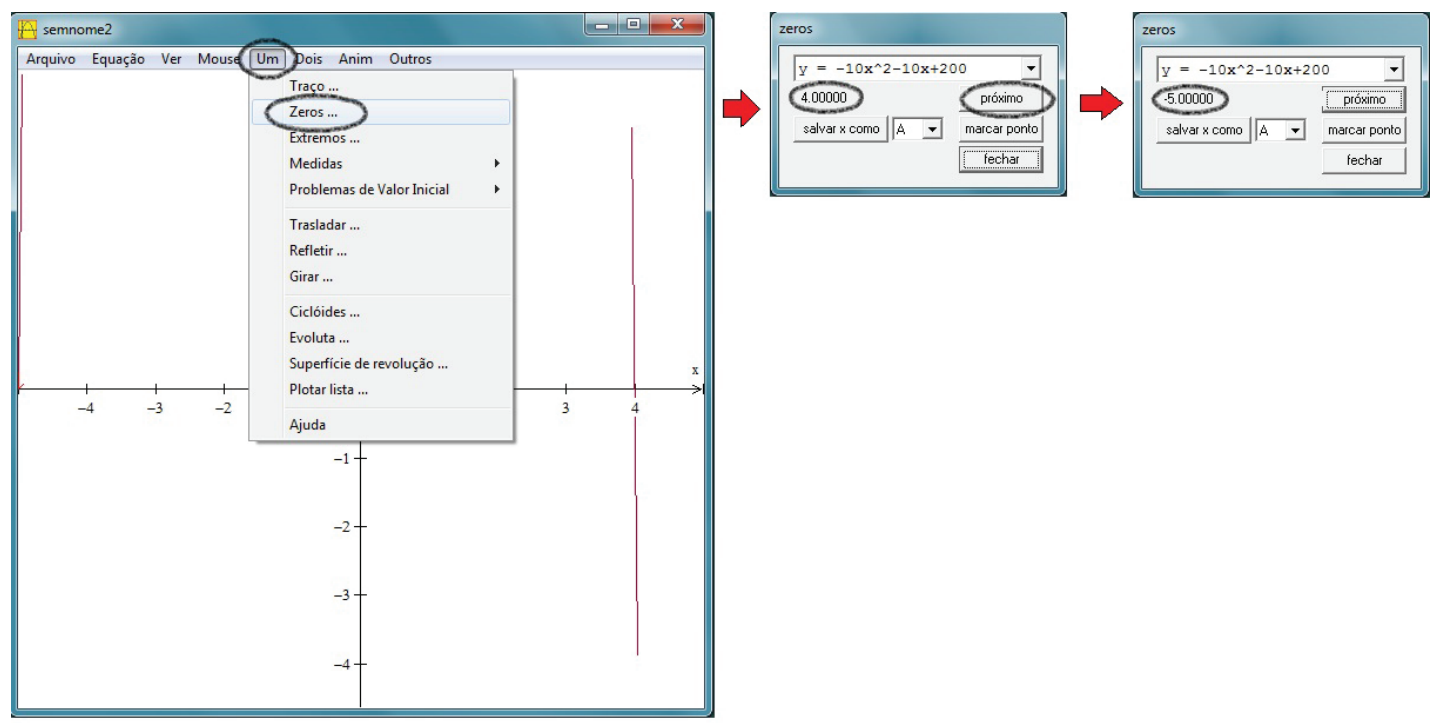

Figura 25: Representação dos zeros da função $R(x)=-10 x^{2}-10 x+200$

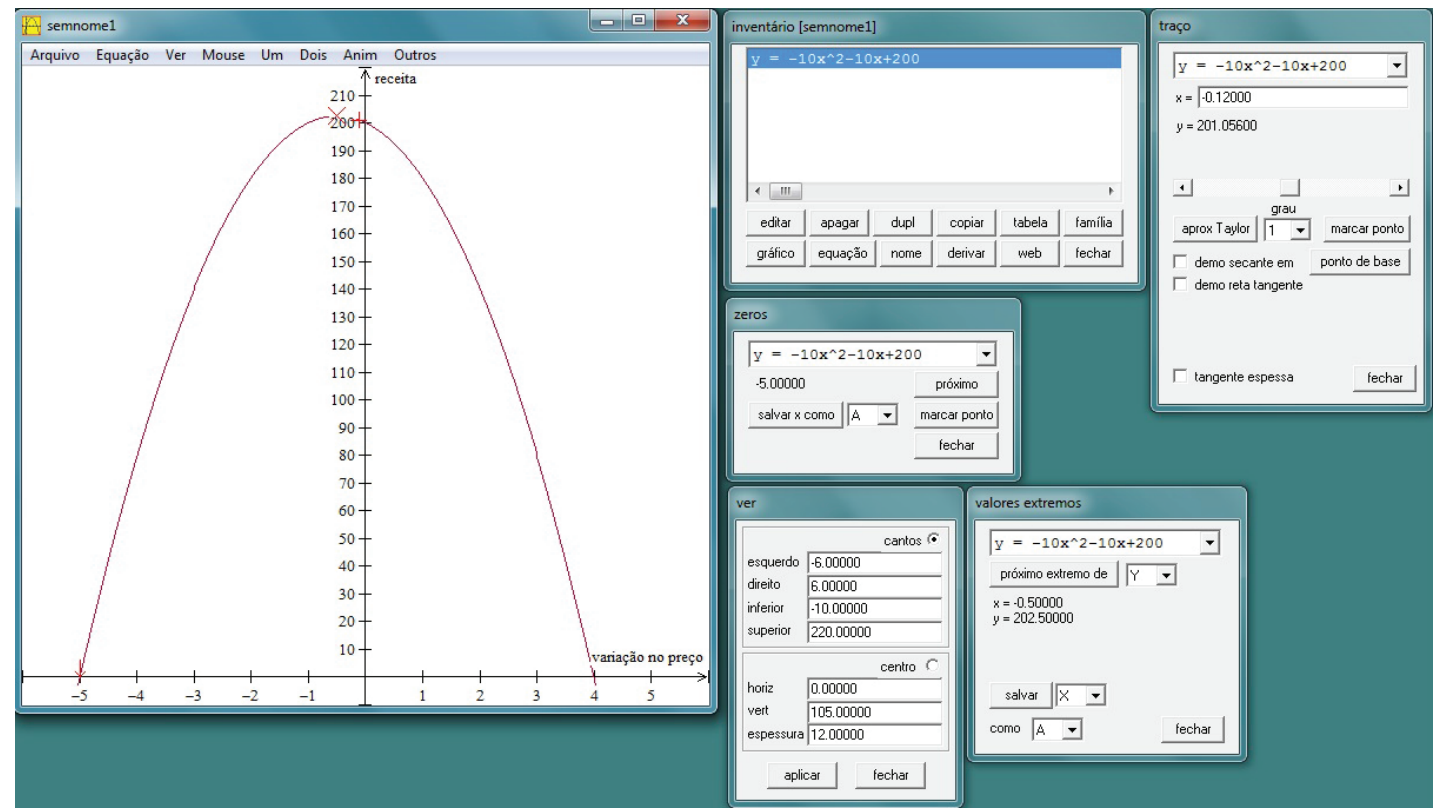

Figura 27: Gráfico da função $R(x)=-10 x^{2}-10 x+200$

entre o número de refeições e o valor de cada refeição, ambos determinados em função da variação no preço da refeição (para mais ou para menos).

Em geral, considerando:

- $k_{1}$ a quantidade inicial (em média) de servidores que almoçam no restaurante do IFTO, $\forall k_{1} \in \mathbb{N}$,

- $k_{2}$ a variação no número de pessoas que almoçam em função da variação no preço da refeição, $\forall k_{2} \in$ $\mathbb{Z}$,

- $k_{3}$ o valor inicial da refeição, $\forall k_{3} \geq 5$ e $k_{3} \in \mathbb{R}$,

- $x$ o valor correspondente à variação do preço da refeição para mais ou para menos, $\forall x \in \mathbb{R}$,

$$
\text { - } x_{v}=-\frac{b}{2 a}, \forall x \in \mathbb{R}
$$

temos:

$$
\begin{aligned}
R(x) & =\left(k_{1}-k_{2} \cdot x\right)\left(k_{3}+x\right) \\
& =k_{1} \cdot k_{3}+k_{1} \cdot x-k_{2} \cdot k_{3} \cdot x-k_{2} \cdot x^{2} \\
& =-k_{2} \cdot x^{2}+\left(k_{1}-k_{2} k_{3}\right) \cdot x+k_{1} k_{3} .
\end{aligned}
$$

Portanto:

- para valores fixos de $\left(k_{1}-k_{2} k_{3}\right)$, quanto maior o valor da variação do número de pessoas, em módulo, menor será a variação no preço da refeição 
para obter receita máxima. E, quanto menor for o valor da variação do número de pessoas, em módulo, maior será a variação no preço da refeição para obter receita máxima;

- em relação ao coeficiente $\left(k_{1}-k_{2} k_{3}\right)$, têm-se dois casos a considerar: quando $k_{2} k_{3}>k_{1}$ e quando $k_{2} k_{3}<k_{1}$. No primeiro caso, o valor de $\left(k_{1}-\right.$ $\left.k_{2} k_{3}\right)<0$ e, portanto, o valor correspondende à variação do preço da refeição será negativo. No segundo caso, o valor de $\left(k_{1}-k_{2} k_{3}\right)>0$, portanto, o valor coorespondende à variação do preço da refeição será positivo;

- o produto $k_{1} \cdot k_{3}$ indica a receita inicial. Portanto, para valores fixos no preço da refeição, quanto maior o produto entre o número de pessoas e o valor inicial da refeição, maior será a receita inical.

\section{Conclusões}

Ao final do trabalho, observou-se que a inserção do computador no processo de ensino e de aprendizagem, em conjunto com o software winplot, configura-se como um recurso didático para as aulas de matemática na medida em que o professor conheça os recursos disponíveis no software. Seu uso pode possibilitar ao aluno a formulação de conjecturas do comportamento do gráfico de uma função quadrática em relação as variações nos parâmetros. Geometricamente, pode-se mostrar ao aluno que, quando os valores da $a$ se aproximam de zero, o gráfico da função quadrática se aproxima de uma reta e, portanto, de uma função afim.

Em cada atividade proposta ao longo do seção 2, percebeu-se que o uso do winplot favorece o trabalho do professor e do aluno nas construções, na vizualização e nas simulações de gráficos para valores diferentes $a, b$ e $c$ da função quadrática $f(x)=a x^{2}+b x+c$. O mesmo pode ser dito com relação à seção 3 , em que foi apresentada uma aplicação da função quadrática. Seu modo interativo para animações de gráficos e a possibilidade de construir, simultaneamente, gráficos de uma família de funções são os recursos de destaque do software. Entretanto o computador não pode ser usado como critério único e absoluto para validação dos resutados matemáticos. Ressaltamos que o software possui algumas limitações no arredondamento e na representação dos resultados em forma fracionária. Portanto, sugere-se a manutenção do tratamento algébrico no decorrer das aulas.

De modo geral, o software winplot revelou-se como uma opção para a inserção no planejamento do professor, visto que apresenta as seguintes características: é de livre domínio, possui uma boa interface gráfica, é de fácil manuseio e possibilita ao usuário construir gráficos variados em um mesmo eixo de coordenadas. Dessa forma, espera-se que as atividades propostas motivem os alunos, favorecendo o desenvolvimento da capacidade de observação, compreensão e construção gráfica de funções quadráticas. Morbi luctus, wisi viverra faucibus pretium, nibh est placerat odio, nec commodo wisi enim eget quam. Quisque libero justo, consectetuer a, feugiat vitae, porttitor eu, libero. Suspendisse sed mauris vitae elit sollicitudin malesuada. Maecenas ultricies eros sit amet ante. Ut venenatis velit. Maecenas sed mi eget dui varius euismod. Phasellus aliquet volutpat odio. Vestibulum ante ipsum primis in faucibus orci luctus et ultrices posuere cubilia Curae; Pellentesque sit amet pede ac sem eleifend consectetuer. Nullam elementum, urna vel imperdiet sodales, elit ipsum pharetra ligula, ac pretium ante justo a nulla. Curabitur tristique arcu eu metus. Vestibulum lectus. Proin mauris. Proin eu nunc eu urna hendrerit faucibus. Aliquam auctor, pede consequat laoreet varius, eros tellus scelerisque quam, pellentesque hendrerit ipsum dolor sed augue. Nulla nec lacus.

\section{Referências bibliográficas}

BASSANEZI, Rodney Carlos. Ensino-aprendizagem com modelagem matemática. São Paulo: Contexto, 2009.

GIRALDO, Victor; MATTOS, Francisco; CAETANO, Paulo. Recursos computacionais no ensino da matemática. Coleção PROFMAT, SBM, 2012.

IEZZI, Gelson. Fundamentos de matemática elementar, I: conjuntos, funções 8. ed. São Paulo: Atual, 2004.

LIMA, Elon Lages. Matemática e ensino. 3. ed. Rio de Janeiro: SBM, 2007.

LIMA, Elon Lages. A matemática no Ensino Médio. 9. ed. Rio de Janeiro: SBM, 2006. v. 1.

BRASIL. Ministério da Educação. Orientações Curriculares para o Ensino Médio. v. 2. Disponível em: $<w w w . p o r t a l . m e c . g o v . b r>$. Acesso em: 13 jun. 2013.

BRASIL. Ministério da Educação. PCN+ Ensino Médio. Orientações Educacionais Complementares aos Parâmetros Curriculares Nacionais - Ciências da Natureza, Matemática e suas Tecnologias. Disponível em: <portal.mec.gov/seb/arquivos/pdf/CienciasNatureza.pdf>. Acesso em: 13 jun. 2013.

BRASIL. Ministério da Educação. Proeja: Documento Base. Disponível em: <http://portal.mec.gov.br/setec/ arquivos/pdf2/proeja_medio.pdf>. Acesso em: 10 jun. 2013. 
INSTITUTO FEDERAL DO TOCANTINS. Oganização Didático-Pedagógico do PROEJA. Disponível em: $<$ palmas.ifto.edu.br/docs/cepiem/odp_proeja.pdf>. Acesso em: 10 jun. 2013.

MOUETTE, Dominique. Aplicação de um software de representação gráfica de equações nas disciplinas de cálculo diferencial e integral. In: XXXIII CONGRESSO BRASILEIRO DE ENSINO DE ENGENHARIA, 1215 set. 2005, Campina Grande. Disponível em: <http:/ / www.abenge.org.br/CobengeAnteriores /2005/artigos/SP-5-05188295881-1118977477489 .pdf>. Acesso em: 13 jun. 2013.

ROCHA, João Silva; LIMA, Izuriana Borges; BARRETO, Fernanda Sá. Atividades propostas na internet pra o ensino da função polinomial de $1^{\circ}$ grau com o uso do software winplot. In: VI ENCONTRO PARAIBANO DE EDUCAÇÃO MATEMÁTICA, 9-11 nov. 2011, Monteiro. Disponível em: <http://www.sbempb.com.br/anais/arquivos /trabalhos/CC-8716291.pdf>. Acesso em: 13 jun. 2013. 